\title{
Sexual Maturation in Male Prairie Voles: Effects of the Social Environment
}

\author{
J. M. MATEO, ${ }^{1}$ W. G. HOLMES, ANGELA M. BELL AND MARJUT TURNER \\ Department of Psychology, University of Michigan, Ann Arbor, MI 48109-1027
}

Received 28 October 1993

\begin{abstract}
MATEO, J. M., W. G. HOLMES, A. M. BELL AND M. TURNER. Sexual maturation in male prairie voles: Effects of the social environment. PHYSIOL BEHAV 56(2) 299-304, 1994. - The effects of various social contexts on sexual maturation in captive male prairie voles were investigated. Sexual maturity was assessed as the ability of a young male to produce urine capable of activating a diestrous adult female into estrus, as females remain anestrus until they ingest a male urinary chemosignal. In five experiments the postweaning social environments of developing males were manipulated (e.g., presence or absence of dam, sire, or junior litter, exposure to unfamiliar adult voles, social isolation) to determine if the age at which males begin to produce potent urine was sensitive to social effects. In general, there was no difference in the age of potent urine production as a function of social environment. Findings are discussed in the context of dispersal, inbreeding avoidance, and mate acquisition.
\end{abstract}

Microtus Prairie voles Social environment Reproductive development Chemosignals

Reproductive activation

IN many species of small rodents, a male's social environment during early development affects when pubertal maturation begins. For example, exposure to unfamiliar adult males delays sexual maturation in male albino house mice $(23,29)$ and prairie deer mice (2). Similarly, sexual maturation is reportedly delayed in prepubertal males housed with siblings [prairie voles $(1,22)$ ] or same-aged unrelated males [bank voles (12); prairie deermice (2)]. Urinary chemosignals appear to mediate social influence, as exposure to soiled bedding alone often delays pubertal maturation $(16,25)$.

The influence of the social environment on sexual maturation is often interpreted in the context of inbreeding avoidance, mate competition, or lifetime reproductive success $(9,11,13,22,25)$. However, few studies have been conducted on male reproductive development in a monogamous species [but see (11)], wherein the sire is often present throughout litter development and both male and female offspring may remain at the natal nest postpubertally. In such systems there is ample opportunity for sexual maturation to be accelerated or delayed by the presence of conspecifics, especially family members, and the occurrence of close inbreeding is possible.

Prairie voles (Microtus ochrogaster) are arvicoline rodents that exhibit monogamy or communal breeding in the field. During the spring and summer, most social units consist of an actively breeding male-female pair and their young offspring. Toward winter, communal groups form, and are often comprised of a breeding pair, their most recent litter, and their adult philopatric offspring (10). Less than half of the young born survive to 30 days and about one-third of the male survivors disperse around 45 days of age (20). Reproductive activation in wild males, de- fined as the presence of scrotal testes, occurs between 29 and 38 days of age (20). Captive males have descended testes by 25 days of age (pers. obs.), and are sexually mature at about 40-45 days of age, depending on the index used $(8,24)$. Females are induced ovulators, but before they will copulate females must be activated into physiological and behavioral estrus by direct contact with adult male urine (5) via the vomeronasal organ (18). Thus, a male must be able to produce urine that is capable of activating a female into estrus (hereafter termed potent urine) before she will mate with him, which indicates that one critical component of male sexual development is the ability to produce potent urine.

Most investigations of the effects of social environment on the timing of sexual maturation in small mammals, including prairie voles, have concentrated on young females $(3,9,13,14,18)$. For example, first vaginal opening is delayed, if not completely absent, when female prairie voles are housed with their families or natal groups, but is accelerated if they are exposed to unfamiliar adult males or their urine. Further, if a recently activated virgin female is exposed to adult females or urine from females, she will return to a diestrous condition [reviewed in (8)]. However, little is known about the accelerating or delaying influence of conspecifics on male reproductive development [but see $(25,29)]$.

The purpose of our study was to examine how exposure to various related and unrelated voles affected the timing of male prairie voles' first production of potent urine. Using a longitudinal design, we evaluated the potency of male urine from 3060 days of age, by determining whether it could activate diestrous adult females into behavioral estrus. A longitudinal approach allowed us to study the development of potent urine pro-

\footnotetext{
${ }^{1}$ To whom requests for reprints should be addressed.
} 
duction in individual males across time, which is not possible when other physiological indices of maturation are used (i.e., testes weights, seminal vesicle weights). Further, if a male prairie vole is producing sperm or has reached adult size, but is not yet producing potent urine, he will not be able to activate a female into reproductive condition, and therefore will not be able to sire offspring.

GENERAL METHOD

\section{Animals}

Prairie voles were laboratory-bred descendants of stock originally derived from a population in South-central Illinois. Animals were housed in polypropylene or stainless steel laboratory cages ( $46 \times 23 \times 15 \mathrm{~cm}$ natal cages or $25 \times 18 \times 13 \mathrm{~cm}$ isolation cages), with pine shavings for bedding. All animals were maintained on a 14:10 light:dark cycle with Purina mouse breeder chow (\#5015) and water available ad lib. Juveniles were sexed at weaning ( 21 days), and subject males were arbitrarily assigned to experimental conditions (details below).

\section{General Procedures}

In each of the five experiments reported, we assessed the potency of a subject male's urine by applying it daily around the nose and mouth of an adult diestrous female and conducting a sexual preference test every 5 days with a "screener" male (not the subject male). This screener male was presented a urinetreated female and a water-treated female under the assumption that the screener male would prefer the urine-treated female only if she had been induced into estrus by the subject male's urine, as detailed below.

At the beginning of each of the five experiments, adult diestrous females ( $>45$ days of age) were assigned to either a urinetreated or water-treated group. Vaginal lavages were taken with a wire loop and tap water to estimate reproductive condition [see (28)]. A urine-treated female received urine from the same subject male throughout the study. Each urine- and water-treated female was housed in its own cage in a room that excluded males.

\section{Urine Collection and Application}

Urine was collected daily (between 0900 and $1200 \mathrm{~h}$ ) from each subject male, starting at 25 days of age. Males were individually removed from their cage and placed in a clean empty polypropylene cage for a few minutes to collect the urine, which was immediately applied to a urine-treated female's oral region (nose, nares, mouth) with a clean paintbrush (5). Water-treated females received similar daily applications of tap water.

\section{Behavioral Tests for Potent Urine (Bioassay)}

Reproductive activation of urine-treated females was assessed with behavioral preference tests conducted once every 5 days, beginning when subject males were 30 days old. We assumed that a female would shift gradually from a diestrous to an estrous condition as the subject male, from which she received urine daily, began to produce potent urine. A preference test consisted of observing a trio of voles in a $25 \times 30 \times 50 \mathrm{~cm}$ glass aquarium: a water-treated female, a urine-treated female, and a screener male. Urine- and water-treated females were tethered to opposite ends of the aquarium (30), whereas the screener male was free to move about the aquarium. Screener males $(n=4)$, permanently housed in their own aquarium in which preference tests were conducted, were sexually experienced adults that had sired litters and readily mounted females that were hormonally induced into estrus.

During a $10-$ min preference test, a trained observer that was blind to the test animals' treatments recorded: the number of body-nose investigations made by the male (his nose touching a body part of the female), the number of anogenital investiga. tions made by each vole (the nose of one vole in contact with the anogenital area of the other), the number of aggressive interactions (lunging, biting, boxing), and the number of times each female was mounted (screener male's forepaws on female's back and thrusting for $>3 \mathrm{~s}$ without female running from male). The location of the screener male was noted every $15 \mathrm{~s}$ to estimate the amount of time he spent in proximity $(<5 \mathrm{~cm})$ to each female.

Vaginal lavages were obtained from each urine-treated and water-treated female before testing as an additional estimate of female reproductive condition (28). The use of vaginal cytology as a definitive estrous assay would perhaps have offered more control than the behavioral tests (which involved additional voles - the screener male and water-treated female), but was rejected because of the unreliability of cytology as an indicator of behavioral receptivity [(28), pers. obs.].

Urine applications (daily) and behavioral testing (every 5 days) were terminated when a screener male showed a clear sexual preference for a urine-treated female over the water-treated female (see next section). We concluded that a female was reproductively activated and that a subject male was producing potent urine when the female being painted with his urine was preferred by a screener male during a behavioral test. If a urinetreated female was not preferred by a screener male by the time her subject male reached 60 days of age, the subject male's data were excluded ( $n=21$ males across the five experiments). Individual differences in female responsiveness to male urinary cues are not uncommon in prairie voles $(6,7)$.

\section{Validating Behavioral Preference Tests}

We conducted three pilot tests to assess the validity of our behavioral preference bioassay. First, we injected females with estradiol $(6,7)$ and compared screener male response to these females vs. noninjected, diestrous females. Second, we induced estrus in females by pairing them with adult males for $20 \mathrm{~h}$ and then housing them in that male's soiled cage alone for an additional $24-30 \mathrm{~h}(18)$. Finally, we painted females with adult male ( $>60$ days of age) urine for 5 days (5) and then conducted preference tests.

These three pilot tests, as well as reports from other investigators $(7,8,28)$, indicated that our bioassay did indeed reveal the change in female reproductive condition, which in turn indicated the potency of subject males' urine. Repeated-measures ANOVAs indicated a significant difference in screener male behaviors directed toward an estrous and diestrous female during pilot tests. Males exhibited a distinct preference for behaviorally estrous females over diestrous females, as indicated by their increase in proximity to $(p<0.01)$, heightened anogenital investigations of $(p<0.05)$, and selective mounting of $\left(\chi^{2}, p<0.05\right)$ the urine-treated females across time. There was no consistent difference in the other behaviors observed during the preference tests. Thus, for the following experiments we concluded that a preference was demonstrated when either a female was mounted, or a screener male directed at least $65 \%$ of his anogenital investigations and $70 \%$ of his proximity time toward one of the two females

\section{Spermatogenesis}

To obtain an additional physiological index of sexual maturation, and to track the development of sperm production, the 
TABLE 1

SUBJECT MALES' SOCIAL ENVIRONMENTS AND AGE AT POTENT-URINE PRODUCTION

\begin{tabular}{|c|c|c|c|c|}
\hline Experiment & Preweaning Social Composition & Postweaning Social Composition & $\begin{array}{c}\text { Age } \\
(\text { Mean } \pm \text { SEM })\end{array}$ & $N$ \\
\hline \multirow[t]{2}{*}{ Experiment 1} & \multirow[t]{2}{*}{ Dam not pregnant and sire absent } & Natal (dam, sibs) or isolate & $44.5 \pm 1.4$ & 10 \\
\hline & & Isolate & $45.8 \pm 1.6$ & 12 \\
\hline \multirow[t]{2}{*}{ Experiment 2} & \multirow[t]{2}{*}{ Dam pregnant and sire present } & Natal (dam, sire, sibs) or isolate & $51.7 \pm 2.4$ & 9 \\
\hline & & Isolate & $53.9 \pm 1.6$ & 9 \\
\hline \multirow[t]{2}{*}{ Experiment 3} & \multirow[t]{2}{*}{ Dam pregnant and sire absent } & Natal (dam, sibs) or isolate & $47.3 \pm 1.8$ & 13 \\
\hline & & Isolate & $46.4 \pm 1.7$ & 11 \\
\hline \multirow[t]{2}{*}{ Experiment 4} & \multirow[t]{2}{*}{ Dam pregnant and sire present } & Natal (dam, sire, sibs) or natal (sire, sibs) & $54.6 \pm 1.9$ & 8 \\
\hline & & Natal (sire, sibs) & $54.4 \pm 1.6$ & 12 \\
\hline \multirow[t]{3}{*}{ Experiment 5} & \multirow[t]{3}{*}{ Dam pregnant and sire present } & Male-exposed/natal, cage-exposed/natal or female-exposed/natal & $44.3 \pm 1.2$ & 13 \\
\hline & & Case-exposed/natal & $44.5 \pm 1.6$ & 13 \\
\hline & & Female-exposed/natal & $48.5 \pm 2.4$ & 11 \\
\hline
\end{tabular}

degree of spermatogenesis was quantified for males 17-62 days of age ( $n=35$ males from second litters produced by dams in Experiment 5). Spermatogenesis is well under way by 35 days of age (24); therefore, we presumed that all subject males were producing fertile sperm by the time they produce potent urine, which they did at about 45 days of age (see below). However, it is not clear if these two events are coupled chronologically. To investigate the association between spermatogenesis and potent urine production, we examined the development of spermatids in males of various ages. Males were sacrificed and their testes immediately removed for histology. Testes were weighed and stored in Bouin's solution. Later testes were dehydrated, embedded in paraffin, sectioned at $5 \mu \mathrm{m}$, and stained with hematoxylin and eosin. Spermatogenesis of slide-mounted testes was quantified using a five-point spermatogenic index (SI), with an SI $>3$ indicating the presence of mature spermatozoa (15).

\section{Analyses}

Because behavioral preference tests occurred every 5 days, the reported ages of potent urine production represent the conservative end of a 5-day age range. For example, if a urine-treated female was mounted when the corresponding subject male was 45 days of age, that male may have started to produce potent urine as early as 41 days of age; thus, the male's urine was potent at least by day 45 . Mean ages \pm SEM of potent urine production are reported and analyzed with a Student's $t$-test. Repeated-measures ANOVAs were conducted on male body weight data (condition $\times$ age). For all analyses $\alpha=0.05$. Statistical comparisons between experiments are not appropriate for two reasons. First, experimental groups often differed by more than one factor. Second, experiments were conducted at various times of the year and animals did respond to subtle seasonal changes, despite the constant laboratory conditions, thus creating differences between subject males across the seasons (17).

\section{EXPERIMENT 1}

\section{Method}

Unrelated males and females were paired to produce subject males; sires were removed within 7 days of insemination. Subject males were raised with their dam and siblings until 21 days of age, when they were arbitrarily assigned to one of two groups. Isolate males $(n=12)$ were housed individually, whereas natal males $(n=10)$ remained with their dam and siblings.

\section{Results}

The age at which males first produced potent urine was not affected by whether they were isolated at weaning or remained in their natal group. The mean ages at which the urine of isolate males ( $45.8 \pm 1.6$ days) and natal males $(44.5 \pm 1.4$ days) was potent did not differ significantly $(t=0.61$, NS) (Table 1 ).

\section{EXPERIMENT 2}

\section{Method}

Given the routine presence of sires at natal nests in nature (20), subject males were again assigned to either the isolate group $(n=9)$ or natal group $(n=9)$, but, unlike Experiment 1 , sires remained in natal cages. Sires copulated with their mates during the postpartum estrus that immediately followed the birth of the subject males, such that a second litter was born at about the time the subject males were weaned ( 21 days).

\section{Results}

There was no significant difference $(t=0.78, \mathrm{NS})$ in the ages of potent urine production of the isolate and natal groups (53.9 \pm 1.6 and $51.7 \pm 2.4$ days, respectively).

\section{EXPERIMENT 3}

There were two differences in the subject males' preweaning environments of Experiments 1 and 2. In Experiment 1, the dam was not gestating, and the sire was absent. The reverse was true for Experiment 2. Experiment 3 was designed to discriminate between these two confounding effects, as puberty in female prairie voles is suppressed by the presence of pregnant females and accelerated by adult males $(5,9)$.

Body weights are reportedly suppressed in juvenile male and female prairie voles housed with siblings, compared with voles housed singly (1). Given the lack of evidence for reproductive suppression in the first two experiments, somatic development was also examined in Experiments 3-5. To determine the effects of siblings and parents on body weights, subject males were weighed every 5 days, beginning at day 25 .

\section{Method}

Sires were absent during the pre- and postweaning development of subject males, but sires were not removed until they inseminated their mate during postpartum estrus (i.e., within 3 


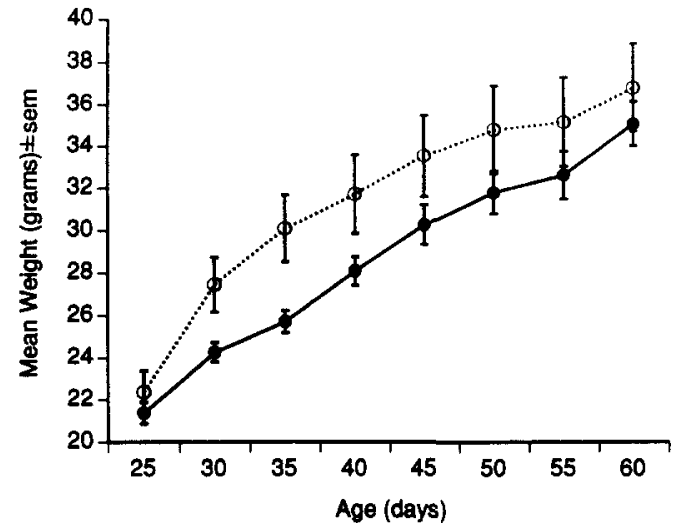

FIG. 1. Mean body weights \pm SEM of natal and isolate subject males in Experiment 3 from 25-60 days of age. Closed circles represent males housed with dam, sire, and siblings during postweaning development; males housed in isolation postweaning are represented by open circles.

days of when subject males were born). Subject males, all of which were reared by a pregnant dam in the absence of their sire, either remained with their dam and siblings at weaning (natal group, $n=13$ ) or they were housed alone at weaning (isolate group, $n=11$ ). Note that this design addresses the effect of a dam's (and siblings') presence during a subject male's postweaning development and eliminates the potential influence of the sire's presence.

\section{Results}

Isolate males attained urine potency at approximately the same age as males in the natal group ( $46.4 \pm 1.7$ vs. $47.3 \pm 1.8$ days, respectively) ( $t=0.38$, NS). Thus, removal from a gestating female's influence did not significantly affect the onset of urine potency. The body weights (Fig. 1) of males housed with dam and siblings ( $n=11)$ compared with males housed in isolation $(n=11)$ did not differ significantly across time, $F(1,20)$ $=2.48$, NS.

\section{EXPERIMENT 4}

Urine from pregnant prairie voles inhibits reproductive development (uterine growth) in virgin females exposed to adult males, which normally stimulates female reproductive development (9). Thus, we sought to determine whether potent urine production in males would also be sensitive to the suppressive cues emitted by pregnant dams. In Experiment 3, isolate males were removed from the cues of both dams and siblings. Experiment 4 eliminates this potential confound by removing the dam from the natal group while the subject male remains with its siblings and sire.

\section{Method}

Subject males were housed with their pregnant dam (inseminated during postpartum estrus), sire, and siblings until weaning. Then dams were removed or left with their natal group. Experiment 4 had to be conducted twice due to the death of nine subject males in the first replicate (two of nine from dam present, seven of 11 from dam absent condition). Carcasses of subject males were found in cages at about the age they began to produce potent urine, based on ages reported in Experiments 1-3. Data presented below are from a second replicate in which three of 12 males died in the dam absent condition after producing potent urine and none of eight males died in the dam present condition Subject males were again weighed every 5 days, this time begin ning at day 5 , to examine the influence of social composition on preweaning somatic growth.

Results

There was no significant difference in the ages at which dam present and dam absent males produced potent urine $(54.6 \pm 1.9$ and $54.4 \pm 1.6$ days, respectively) $(t=0.08$, NS). Therefore, it appears that urine from pregnant females does not inhibit male postweaning sexual development as it does peripubertal female voles. Removal of the dam at weaning had no significant effect on the body weights of juvenile males 5-60 days of age, $F(1$, 23) $=0.847$, NS (Fig. 2).

\section{EXPERIMENT 5}

Reproductive maturation in captive female prairie voles housed with their parents and siblings is suppressed, but if females housed in their natal environment are exposed several times to an unfamiliar adult male for a few hours/day, the suppressive effects of the females' natal environment are reversed (14). In nature, male prairie voles remain with their family group following weaning, but they routinely encounter unfamiliar adult males and females when the immature males explore the home range of their family group, especially its periphery (20). Thus, we sought to determine for males living with their family group if the age at which they first produced potent urine would be affected by daily exposure to either unfamiliar adult males or unfamiliar estrous females.

\section{Method}

Throughout this experiment, subject males were housed with their dam, sire, and siblings, but starting at 25 days of age, males were removed daily from their natal cage for $1 \mathrm{~h}$ (between 1000 and $1400 \mathrm{~h}$ ). During this 1 -h period, male-exposed subjects $(n=$ 13) were placed with an unfamiliar adult male ( $>60$ days old) in the adult's home cage, and cage-exposed males $(n=13)$ were placed in an empty cage with clean bedding. Female-exposed males $(n=11)$ were placed in the home cage of an unfamiliar adult female primed with estradiol benzoate (EB). The EB (obtained from Sigma Chemicals, St. Louis, MO) was suspended in

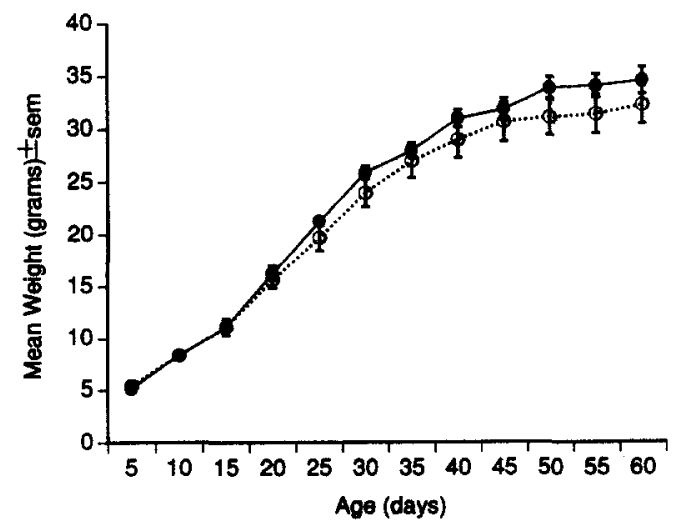

FIG. 2. Mean body weights \pm SEM of dam-present and dam-absent subject males in Experiment 4 from 5-60 days of age. Open circles represent males housed with dam, sire, and siblings during postweaning development; closed circles represent males remaining in natal unit with dam removed at weaning. 
sesame oil $(6.6 \mu \mathrm{g} / 0.05 \mathrm{ml})$ and injected SC. Behavioral estrus in EB-treated females was verified by observing them in sexual preference tests with screener males that routinely mounted the females. To simulate field conditions, male-exposed and femaleexposed subjects were rotated daily among different adults of the appropriate sex.

\section{Results}

Nonsystematic observations during daily 1-h exposure periods indicated that adult males were rarely agonistic towards subject males, and often rested in contact with them, even as the younger males approached maturity. Subject males appeared to spend less time in proximity to EB-treated females, but some did attempt to mount females in the final stages of the study.

Daily exposure to neither an unfamiliar adult male nor an unfamiliar estrous female affected the age of potent urine production in male prairie voles. There was no significant difference $(t=-0.08, \mathrm{NS})$ in the age of potency between male-exposed (44.3 \pm 1.2 days) and cage-exposed (44.5 \pm 1.6 days) males. Similarly, there was no significant difference between femaleexposed males ( $48.5 \pm 2.4$ days) and either cage-exposed males $(t=1.42, \mathrm{NS})$ or male-exposed males $(t=1.64, \mathrm{NS})$. This suggests that sexual maturation in female prairie voles (14) but not males (Table 1) is influenced by exposure to unfamiliar conspecifics. The growth patterns paralleled those of Experiments 3 and 4. Spermatogenesis was highly correlated with age $(r=0.796)$ and body weight $(r=0.829)$. All males more than 35 days of age had an $S I \geq 3$ and all males 45 days of age and older had SIs $\geq 4$.

\section{DISCUSSION}

We found no evidence that the postweaning social environments influenced the age of onset of potent urine production or of somatic growth in male prairie voles. Variations in the composition of the natal group (presence or absence of dam, sire, and/or siblings) yielded no significant differences within each experiment using our assay of sexual maturation, the age at which a male first produced urine that could activate estrus. In addition, exposing juvenile males to unfamiliar adults had no discernible impact on the age of production of potent urine. Our results for males contrast with those for female prairie voles. Puberty in females, as normally measured by uterine weight, can be accelerated or delayed by a variety of social factors $(4,9,13,14)$, including exposure to dams, sires, and unfamiliar adults of both sexes. In other rodent species, the rate of male reproductive development is sensitive to males' early social environment $(2,12,16,22,23,25,29)$.

It is possible that the production of potent urine by male prairie voles is unresponsive to changes in their immediate social environment, but does respond to other environmental cues, such as photoperiod, ambient temperature, or food availability $(3,24)$. Alternatively, a different index of sexual maturation, such as spermatogenesis or testis weight, might show sensitivity to vari- ations in males' social environment. Note, however, that body weights (Figs. 1 and 2) of subject males were not significantly influenced by social factors. Males raised in family groups had growth rates comparable to isolated males, and males in all groups had scrotal testes by 25 days of age. These gross levels of analysis contrast with previous reports concerning male maturation in proximity to related individuals $(1,8)$.

The timing of potent urine production and sexual maturation in prairie voles can be viewed in the context of inbreeding avoidance. Laboratory-reared male prairie voles can manifest clear signs of all stages of spermatogenesis by 35 days of age [(24), present data] and our results (Table 1) demonstrate that regardless of the social environment in which males are reared they produce potent urine by about 45 days of age. (Recall that the mean ages of urine potency reflect the conservative end of a 5-day age range.) In nature, males have scrotal testes at 30-35 days of age and may be fertile as early as 42 days of age (19). Male prairie voles that disperse from their natal area do so at about 45 days of age, but about $70 \%$ of males remain at their natal nest until death (20). Collectively, these facts suggest that reproductively mature males live routinely with close genetic relatives (e.g., with sisters and dams while in communal groups) (10). Nevertheless, inbreeding is rare (4), not because males or females disperse before achieving reproductive maturity $(20)$, but because females do not investigate the anogenital region of their mature brothers (26) and thus do not ingest the male urinary chemosignal that would activate them into estrus. In addition, both parents and younger siblings may benefit from the care philopatric juveniles give to pups (27). Therefore, if there were ecological constraints on dispersal, males might gain indirect fitness benefits by exhibiting helping behavior.

We conclude that young male prairie voles are likely to be sexually mature before their natal dispersal and thus are likely to live near their close kin as sexually mature individuals. Despite this, there may be little cost to male maturation prior to dispersing; for example, females avoid inbreeding via behavioral mechanisms. (However, the level of aggression directed toward young males in the wild as they become sexually mature remains unknown.) In fact, males in this short-lived species may realize a reproductive benefit by being sexually competent prior to dispersal. That is, males would gain a reproductive benefit if they could attract, activate, and inseminate a female when the opportunity first arose shortly after dispersal.

\section{ACKNOWLEDGEMENTS}

We thank Randy Nelson for providing the breeding stock that made our research possible. We thank Philip Myers for serving as coadviser to A.M.B. and M.T. during their honors thesis projects in the Biology Department, portions of which are reported here. We thank Sue Carter and Lowell Getz for conversations about their prairie vole research and preprints of their recent work. We thank Theresa Lee, Leslie Meek, and two anonymous reviewers for comments on this manuscript. Our research was supported by funds from the Office of the Vice President for Research to W.G.H. and by a National Science Foundation Graduate Fellowship to J.M.M.

\section{REFERENCES}

1. Batzli, G. O.; Getz, L. L.; Hurley, S. S. Suppression of growth and reproduction of microtine rodents by social factors. J. Mamm. 58:583-591; 1977.

2. Bediz, G. M.; Whitsett, J. M. Social inhibition of sexual maturation in male prairie deer mice. J. Comp. Physiol. Psychol. 93:493-500; 1979.

3. Bronson, F. H. Mammalian reproductive biology. Chicago: University of Chicago Press; 1989.
4. Carter, C. S.; Witt, D. M.; Thompson, E. G.; Carlstead, K. Effects of hormonal, sexual, and social history on mating and pair bonding in prairie voles. Physiol. Behav. 44:691-697; 1988.

5. Carter, C. S.; Witt, D. M.; Auksi, T.; Casten, L. Estrogen and the induction of lordosis in female and male prairie voles (Microtus ochrogaster). Horm. Behav. 21:65-73; 1987.

6. Carter, C. S.; Witt, D. M.; Schneider, J.; Harris, Z. L.; Volkening, D. Male stimuli are necessary for female sexual behavior and uterine 
growth in prairie voles (Microtus ochrogaster). Horm. Behav. 21:74-82; 1987.

7. Carter, C. S.; Getz, L. L.; Gavish, L.; McDermott, J. L.; Arnold, P. Male-related pheromones and activation of female reproduction in the prairie vole (Microtus ochrogaster). Biol. Reprod. 23:1038$1045 ; 1980$.

8. Carter, C. S.; Getz, L. L.; Cohen-Parsons, M. Relationships between social organization and behavioral endocrinology in a monogamous mammal. Adv. Stud. Behav. 16:109-145; 1986.

9. Getz, L. L.; Dluzen, D.; McDermott, J. L. Suppression of reproductive maturation in male-stimulated virgin female Microtus by a female urinary chemosignal. Behav. Proc. 8:59-64; 1983.

10. Getz, L. L.; McGuire, B.; Pizzuto, T.; Hofmann, J. E.; Frase, B. Social organization of the prairie vole Microtus ochrogaster. J. Mamm. 74:44-58; 1993.

11. Gubernick, D. J.; Nordby, J. C. Parental influences on female puberty in the monogamous California mouse, Peromyscus californicus. Anim. Behav. 44:259-267; 1992.

12. Gustafsson, T. O.; Andersson, C. B.; Nyholm, N. E. I. Comparison of sensitivity to social suppression of sexual maturation in captive male bank voles, Clethrionomys glareolus, originating from populations with different degrees of cyclicity. Oikos. 41:250-254; 1983.

13. Hasler, M. J.; Nalbandov, A. V. The effect of weanling and adult males on sexual maturation in female voles (Microtus ochrogaster). Gen. Comp. Endocrinol. 23:237-238; 1974.

14. Hofmann, J. E.; Getz, L. L. Multiple exposures to adult males and reproductive activation of virgin female Microtus ochrogaster. Behav. Proc. 17:57-61; 1988.

15. Holmes, W. G. Body fat influences sexual maturation in captive male Belding's ground squirrels. Can. J. Zool. 66:1620-1625; 1988.

16. Lawton, A. D.; Whitsett, J. M. Inhibition of sexual maturation by a urinary pheromone in male prairie deer mice. Horm. Behav. 13:128$138 ; 1979$.

17. Lee, T. M.; McClintock, M. K. Female rats in a laboratory display seasonal variation in fecundity. J. Reprod. Fertil. 77:51-59; 1986.

18. Lepri, J. J.; Wysocki, C. J. Removal of the vomeronasal organ disrupts the activation of reproduction in female voles. Physiol. Behav. $40: 349-355 ; 1987$
19. Martin, E. P. A population study of the prairie vole (Mi.rotus ach rogaster) in northeastern Kansas. Univ. Kansas Publ. Mus. Nat. Hist. $8: 361-416 ; 1956$.

20. McGuire, B.; Getz, L. L.; Hofmann, J. E.; Pizzuto, 'T.; Frase, B. Natal dispersal and philopatry in prairie voles Microtus ochrogaster in relation to population density, season, and natal social environment Behav. Ecol. Sociobiol. 32:293-302; 1993.

21. McGuire, B.; Pizzuto, T.; Getz, L. L. Patterns of visitation in prairie voles (Microtus ochrogaster) reveal a role for males in population regulation. In: Tamarin, R. H.; Ostfeld, R. S.; Pugh, S. R.; Bujalska, G., eds. Social systems and population cycles in voles. Boston: Birkhauser Verlag; 1990:89-100.

22. McGuire, M. R.; Getz, L. L. Incest taboo between sibling Microtus ochrogaster. J. Mamm. 62:213-215; 1981.

23. McKinney, T. D.; Desjardins, C. Intermale stimuli and testicular function in adult and immature house mice. Biol. Reprod. 9:370$378 ; 1973$.

24. Nelson, R. J. Photoperiodic influences reproduction in the prairie vole. Biol. Reprod. 33:596-602; 1985.

25. Rissman, E. F.; Sheffield, S. D.; Kretzmann, M. B.; Fortune, J. E.; Johnston, R. E. Chemical cues from families delay puberty in male California voles. Biol. Reprod. 31:324-331; 1984.

26. Smale, L.; Pedersen, J. M.; Block, M. L.; Zucker, I. Investigation of conspecific male odours by female prairie voles. Anim. Behav. 39:768-774; 1990.

27. Solomon, N. G. Current indirect fitness benefits associated with philopatry in juvenile prairie voles. Behav. Ecol. Sociobiol. 29:277$282 ; 1991$.

28. Taylor, S. A.; Salo, A. L.; Dewsbury, D. A. Estrus induction in four species of vole (Microtus). J. Comp. Psych. 106:366-376; 1992.

29. Vandenbergh, J. G. Pheromonal regulation of puberty. In: Vandenbergh, J. G., ed. Pheromones and reproduction in mammals. New York: Academic Press; 1983:95-112.

30. Webster, D. G.; Williams, M H.; Dewsbury, D. A. Female regulation of choice in the copulatory behavior of montane voles (Microtus montanus). J. Comp. Physiol. Psychol. 96:661-667; 1982. 